\title{
Combination of 3D printing and injection molding: Overmolding and overprinting
}

\author{
R. Boros, P. Kannan Rajamani, J. G. Kovács* \\ Department of Polymer Engineering, Faculty of Mechanical Engineering, Budapest University of Technology and \\ Economics, Müegyetem rkp. 3., H-1111 Budapest, Hungary
}

Received 8 March 2019; accepted in revised form 21 May 2019

\begin{abstract}
Nowadays, two of the most important polymer processing technologies are injection molding and 3D printing. Injection molding is ideal for mass production, while 3D printing is ideal for producing products with a complicated geometry. When these two technologies are combined, such complex products can be manufactured economically that would be too costly if produced traditionally. We present the possibilities of combining injection molding and 3D printing. We introduced a novel concept to study and compare the bonding strength of polylactic acid (PLA) parts prepared by overprinting and overmolding. We developed a special injection mold for overmolding, with which we injection molded ribs on a preform. The geometry of the overprinted part was similar for comparability. The thermal properties of the samples were determined by differential scanning calorimetry and thermogravimetric analysis. To analyze the strength of mechanical bonding, we developed a rib pull-off test. We tested all four manufacturing combinations with this test: overmolding onto a molded or printed plate and also overprinting onto a molded or printed plate.
\end{abstract}

Keywords: processing technologies, overprinting, overmolding, 3D printing, injection molding

\section{Introduction}

In recent years, poly(lactic acid) (PLA) has attracted a great deal of interest in the field of renewable and biodegradable polymeric materials. PLA is a thermoplastic polymer made from lactic acid and has mainly been used in areas where biodegradability is important, such as the packaging, textile and automotive industries [1]. PLA exhibits good mechanical strength and processability [2, 3]. Lim et al. [4] reviewed the structural, thermal, crystallization and rheological properties of PLA in relation to its manufacturing process. They discussed extrusion, injection molding, blow molding, casting, thermoforming and some other technologies. PLA as a filament for $3 \mathrm{D}$ printing has many advantages over other alternative polymers, such as its low level of shrinkage and relatively low melting temperature. Low shrinkage results in a minimum level of residual stresses in the printed parts, eliminating deformation and delamination, while low melting temperature allows higher productivity of the printing processes [5].

In the past, large plastic components with functional or esthetic parts required a two-piece assembly - an injection molded part with mechanical interlocking, adhesive bonding or welding [6-8]. These techniques can be time-consuming and labor-intensive [9]. However, in the past decade, researchers have proposed several technologies that incorporate the injection molding process to manufacture hybrid parts. A two-piece assembly can be done by overmolding and then no mechanical interlocking or adhesive bonding etc. is necessary [10].

Overmolding is the process in which commonly a previously injected rigid thermoplastic substrate is 
overmolded with a more flexible thermoplastic material. A component is first molded with a regular injection mold and then it is either manually or automatically inserted into another mold cavity before injecting the second-stage polymer. The finished polymer component is a single piece with very different mechanical properties. It must be safely and permanently bonded together throughout its useful life [11]. The process is important when several characteristics have to be merged in the same component to increase its functionality. These can be mechanical strength, pleasant touch or a non-slip surface, cushioning against vibration or impact, or esthetic factors [12-15]. The rigid polymer substrate provides the basic mechanical properties for structural purposes, while the soft polymer cover adds the desired user comfort and product functionalities. Examples of such applications can be seen in automotive interiors, medical devices, telephone keypads, toothbrushes, shaving hardware, household appliances and hand tools $[16,17]$.

While the manufacturing process and the performance of the components in these methods are wellcontrolled and understood, the ability to control the complex internal structure and create tailored properties are limited [18]. Therefore, the use of additive manufacturing ( $\mathrm{AM}$ ) or $3 \mathrm{D}$ printing is preferred because the process allows fabricating complex composite structures with precisely controlled geometry. Thus, 3D printing of composites provides an excellent combination of process flexibility and high-performance products [19]. Tymrak et al. [20] compared the mechanical properties of 3D printed PLA and ABS and concluded that the 3D printed PLA contains less internal stresses and thereby shows better mechanical properties, where the mean tensile strength of the samples is $28.5 \mathrm{MPa}$ for ABS and 56.6 MPa for PLA.

3D printing translates computer-aided design (CAD) 3D models into physical objects. By slicing CAD images digitally, a 3D printer builds objects layer by layer without the need for molds or machining. Polymers used in 3D printing include thermoplastics, thermosets, elastomers, hydrogels, polymer blends, composites and functional polymers [21,22]. 3D printing offers many advantages in the fabrication of polymer composites, including almost unlimited complexity of product geometry, customizability and it is also cost-effective [23]; printers and materials are also widely accessible. However, most $3 \mathrm{D}$ printed polymer products are still used as conceptual prototypes rather than functional components, since pure polymer products built by 3D printing lack strength and functionality [24]. Such limitations restrict the industrial use of 3D printed polymers. Another important drawback of 3D printing is that it is difficult to use in mass production $[25,26]$. Although there are many processes for direct production, none can compete with real mass production technologies, such as injection molding, especially when the mold is printed [27]. The main disadvantage of injection molding is that the complexity of the shapes of products is limited - 3D printing, however, does not have this limitation.

In a novel 3D printing concept developed by Markforged, which was patented in 2017 [28], continuous carbon fiber-based preforms are 3D printed and are then overmolded with thermoplastic to make the product strong, light and to decrease production times. The rigid polymer substrate provides the basic mechanical properties for structural purposes, while the injection overmolded material adds the desired functionality and user comfort.

The fabrication concepts developed in our paper consist of the application of a 3D printed thermoplastic material as an insert for overmolding. We researched and further developed the joining of the two components to achieve better connection between injection molded and 3D printed pars. This way we are combining the advantages of the two technologies by uniting the components into one single polymer part. The main purpose of our work is to evaluate and increase the effectiveness of this novel combination technique and examine the methods of joining the two components. We also studied the properties at the intersections, and the thermal, mechanical and other properties of the prepared components.

\section{Materials, processing and experimental}

Since our goal was to combine the advantages of injection molding and 3D printing, we chose a material that can be processed well with both technologies. We selected PLA 3100HP (Ingeo 3100HP, Nature Works) for injection molding and PLA 040 (PLA 040, Filamania Ltd.) for 3D printing.

We performed DSC tests (DSC Q2000, TA Instruments Inc.) on the materials to analyze their properties for our experiments (Figure 1). The DSC test showed that the melting temperature of PLA 3100HP 


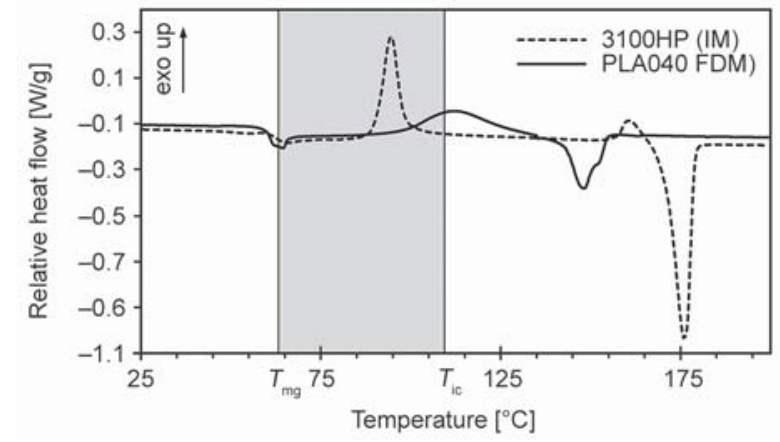

Figure 1. DSC curves of PLA $3100 \mathrm{HP}$ and PLA $040\left(T_{\mathrm{mg}} \approx\right.$ $60^{\circ} \mathrm{C}$, which is the midpoint of the glass transition temperature and $T_{\mathrm{ic}} \approx 110^{\circ} \mathrm{C}$ which is the onset temperature, the measurable start of crystallization).

is $175^{\circ} \mathrm{C}$, therefore $180^{\circ} \mathrm{C}$ was chosen for the lowest melt temperature. We also carried out the TGA tests (TGA Q500, TA Instruments Inc.) at several temperatures to calculate the loss in mass as a function of time.

The materials were dried in a hot-air drier (KDCL) at $80^{\circ} \mathrm{C}$ for 6 hours before they were used. We produced $80 \mathrm{~mm} \times 80 \mathrm{~mm} \times 2 \mathrm{~mm}$ preforms from PLA $3100 \mathrm{HP}$ at a melt temperature of $210^{\circ} \mathrm{C}$ on an Arburg Allrounder 270S (ARBURG Holding GmbH, Lossburg, Germany) injection molding machine. The mold has two cavities, and its temperature was varied between 30 and $120^{\circ} \mathrm{C}$. We printed $80 \mathrm{~mm} \times 80 \mathrm{~mm}$ $\times 2 \mathrm{~mm}$ plates with a Craftbot Plus (CraftUnique Ltd., Budapest, Hungary) FDM printer. The filament was $1.75 \mathrm{~mm}$ diameter PLA 040, nozzle temperature was $215^{\circ} \mathrm{C}$, platform temperature was $60^{\circ} \mathrm{C}$, layer thickness was $0.2 \mathrm{~mm}$ and filling was $100 \%$.

After the preforms were cooled, we injection molded PLA $3100 \mathrm{HP}$ on them with an Arburg Allrounder 370S 700-250 (ARBURG Holding GmbH, Lossburg, Germany) or printed PLA 040 on them with the
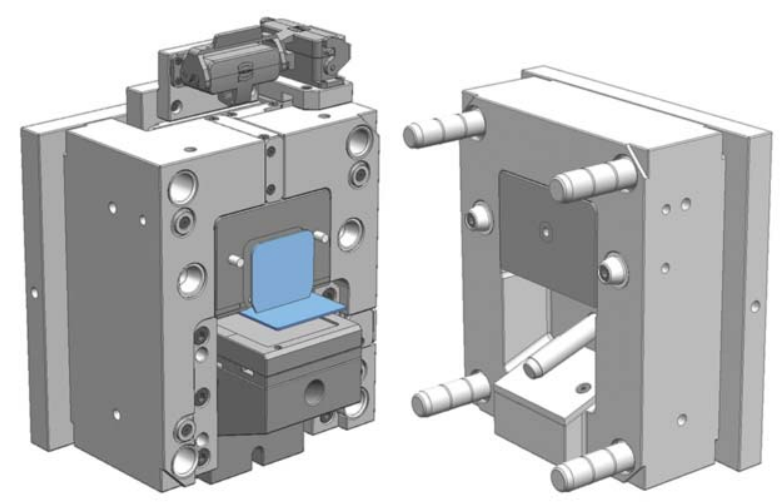

Figure 2. Injection mold with the slider for overmolding.

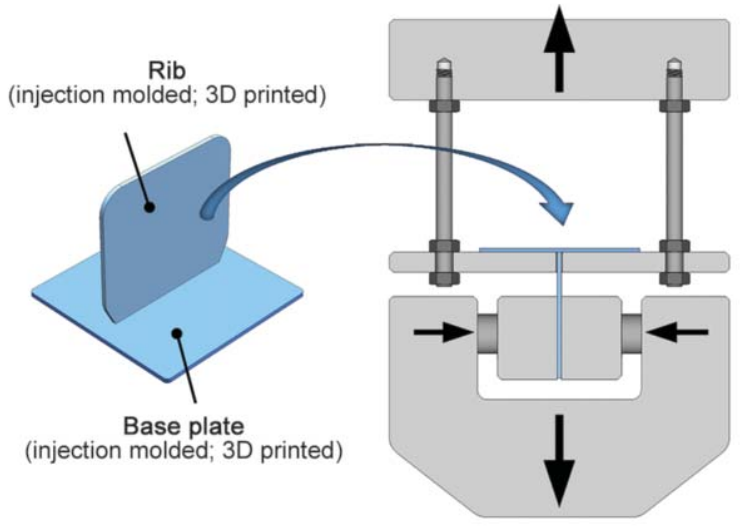

Figure 3. Part with the base plate and rib and the special grip for the measurement of tear-off strength.

Craftbot Plus FDM printer. For overmolding, we developed and produced a special mold with a slider (Figure 2), which can accommodate the $80 \mathrm{~mm} \times$ $80 \mathrm{~mm} \times 2 \mathrm{~mm}$ preforms and create a rib in the middle. The mold can be used without the preform as well, therefore we manufactured (both parts injection molded together) the references with it.

We measured the surface roughness of our samples ( $R_{\mathrm{a}}$ and $R_{\mathrm{z}}$ ) with a Mitutoyo SJ 400 (Kawasaki, Japan) surface roughness tester. We carried out a tensile test on the samples with a special layout (Figure 3) to find the relationship between technological parameters and the strength of the bond. The tensile tests were performed on a Zwick Z050 (Ulm, Germany) universal tester at room temperature and a relative humidity of $50 \%$. The preforms were laid on a plate with a gap and the ribs were fixed with the clamp. The gap is $1 \mathrm{~mm}$ larger than the rib on each side. The connecting surface of the preform and the rib is $120 \mathrm{~mm}^{2}$.

\section{Results and discussion}

The next sections show the results of overmolding onto a molded or printed plate and overprinting onto a molded or printed plate.

\subsection{Overmolding onto molded plate}

In overmolding, melt temperature was varied between 180 and $250{ }^{\circ} \mathrm{C}$. The processes in the cavity were controlled with the help of pressure sensors and fitted to a pressure curve that we set as reference. The reference pressure curve is a result of settings with which we achieved optimal part quality without any injection molding defects. During the tests, we varied the switchover point, the holding time and holding pressure in a range of $\pm 10 \%$ compared to this. As reference for the series with different technological 
settings, we manufactured specimens without a preform, filling the whole cavity, from PLA $3100 \mathrm{HP}$ with melt temperatures of $180,190,210,230$ and $250^{\circ} \mathrm{C}$. With each setting, we manufactured 10 samples. In order to examine the repeatability of the process, we compared two series manufactured with the same technological settings. Melt temperature was set to $190^{\circ} \mathrm{C}$ and mold temperature was set to $30^{\circ} \mathrm{C}$, while preforms were stored at $50 \%$ relative humidity. We performed an F-test and found no significant differences between the variances of the two series of strengths. Then we used a two-sample t-test (assuming identical variances) and obtained that the tearoff strength of the two series did not differ significantly at the $95 \%$ confidence level $(p=0.066)$, therefore we concluded that the repeatability of manufacturing is adequate to support our claims.

The tensile test results of samples - injection molded as one piece - indicated that in the technologically relevant range, melt temperature does not have a significant effect on tensile strength. On the contrary, in the case of overmolded ribs, bond strength increases as melt temperature increases (Figure 4), where the differences were shown with an ANOVA test $(p=0.000156)$.

There is a temperature limit above which tear-off strength slightly decreases in the case of reference samples, or increases less dramatically in the case of overmolded samples. To investigate this change, we performed TGA (TGA Q500, TA Instruments Inc.) tests at several constant temperatures (Figure 5). Curves measured at 190 and $210^{\circ} \mathrm{C}$ did not indicate significant mass loss in the residence time range used in injection molding ( $\sim 30 \mathrm{~min})$, whereas the curves measured at 230 and $250^{\circ} \mathrm{C}$ showed increasing mass loss. Such mass loss indicates considerable

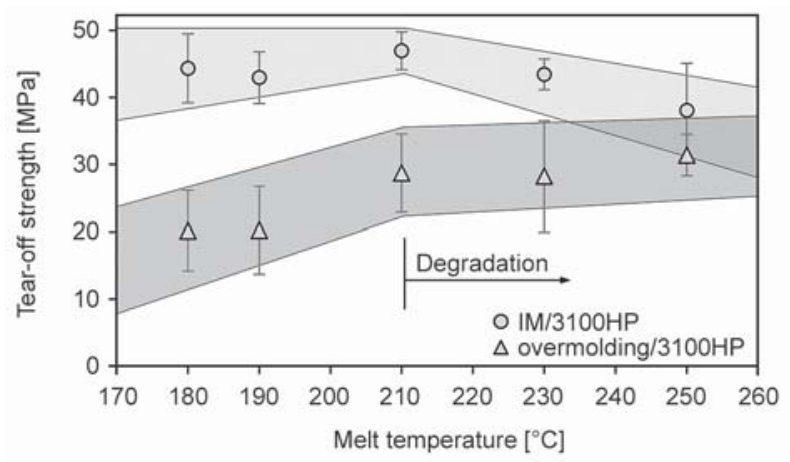

Figure 4. The tensile strength of samples overmolded on the preform (overmolding/3100HP) and injection molded as one (IM/3100HP) as a function of melt temperature.

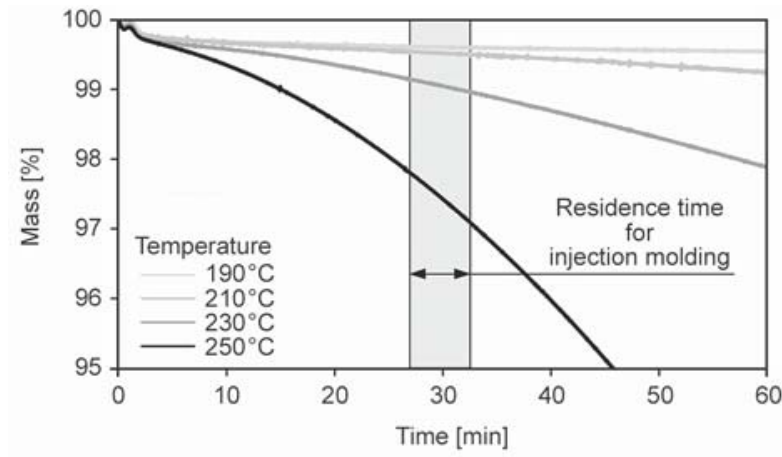

Figure 5. Isothermal TGA curves for the PLA 3100HP material.

degradation, which explains the decrease in tear-off strength.

We produced flat preforms from PLA $3100 \mathrm{HP}$ in a two-cavity mold at a melt temperature of $210^{\circ} \mathrm{C}$. In the case of PLA, we examined the technologically relevant mold temperature range of 30 to $120^{\circ} \mathrm{C}$ with $15^{\circ} \mathrm{C}$ steps. At 75 and $90^{\circ} \mathrm{C}$, the flat specimens suffered such a high degree of deformation that they were unusable. In these cases, the specimens could not be manufactured even with a drastic increase of cooling time. The DSC test of PLA 3100HP (Figure 1) showed that the temperature range in which parts of adequate quality cannot be manufactured is between the midpoint of the glass transition temperature $\left(T_{\mathrm{mg}} \approx 60^{\circ} \mathrm{C}\right)$ and onset temperature, the measurable start of crystallization $\left(T_{\mathrm{ic}} \approx 110^{\circ} \mathrm{C}\right)$. These results are in agreement with the results of Li et al. [29], who also experienced part ejection problems in a similar mold temperature range.

A major part of the cycle time of the injection molding of preforms is cooling time $\left(t_{\text {cooling }}\right)$. Cooling time can be calculated analytically by Equation (1):

$t_{\text {coolingt }}=\frac{s^{2}}{\pi^{2} a_{\text {eff }}} \cdot \ln \left(\frac{4}{\pi} \cdot \frac{T_{\text {melt }}-T_{\text {mold }}}{T_{\text {ejection }}-T_{\text {mold }}}\right)$

where $t_{\text {cooling }}$ [s] is cooling time, $s[\mathrm{~mm}]$ is the wall thickness of the part, $T_{\text {melt }}\left[{ }^{\circ} \mathrm{C}\right]$ is melt temperature, $T_{\text {mold }}\left[{ }^{\circ} \mathrm{C}\right]$ is mold temperature, $T_{\text {ejection }}\left[{ }^{\circ} \mathrm{C}\right]$ is the temperature of the material at ejection, and $a_{\mathrm{eff}}$ $\left[\mathrm{mm}^{2} / \mathrm{s}\right]$ is the effective thermal conductivity of the material.

As mold temperature is increased, the time to reach ejection temperature increases considerably (Figure 6). We injection molded PLA $3100 \mathrm{HP}$ on PLA $3100 \mathrm{HP}$ preforms manufactured with mold temperatures below $60^{\circ} \mathrm{C}$ and above $105^{\circ} \mathrm{C}$, and melt temperature being $210^{\circ} \mathrm{C}$, and performed tensile tests. In the temperature range up to $60^{\circ} \mathrm{C}$, we showed 


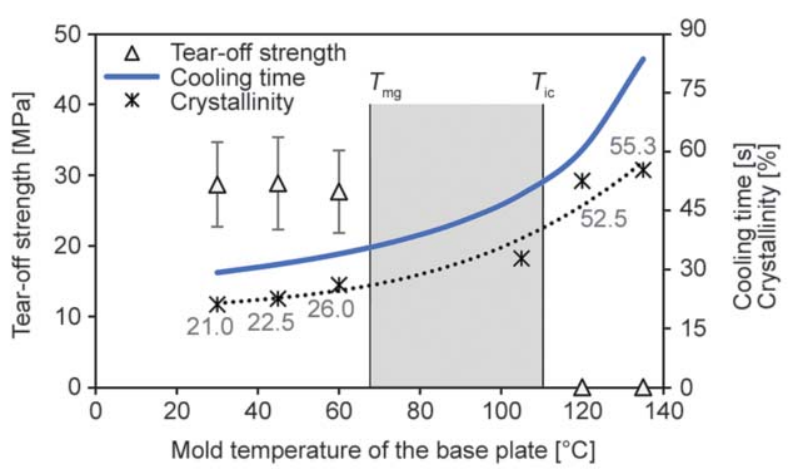

Figure 6. The tensile strength of specimens manufactured with different mold temperatures and a melt temperature of $210^{\circ} \mathrm{C}$, the time necessary to reach ejection temperature, and the crystalline fraction of the samples ( $T_{\mathrm{mg}}-$ midpoint of the glass transition temperature, $T_{\text {ic }}$ - onset temperature, measurable start of crystallization).

with ANOVA that there are no significant differences in tensile strength; the parts welded together well. (Figure 7a). In the case of mold temperatures above $105^{\circ} \mathrm{C}$, there was no bonding between the preforms and the overmolded parts at all; they came out of the mold as separate parts (Figure 7b).

We took material samples for the DSC tests from the preforms manufactured with different mold temperatures. The samples were taken from the position of the planned overmolding area. Using the test results, we calculated the crystalline fraction for each mold temperature, which increased as we had expected (Figure 6). A considerable portion of the heat of the melt goes to the mold because of cooling, part of it heats the preform and a little part of it melts the crystalline fraction. This is the so-called latent heat, which the melt was able to provide in the case of preforms with a lower crystalline fraction (that is, manufactured in a colder mold), while in the case of preforms

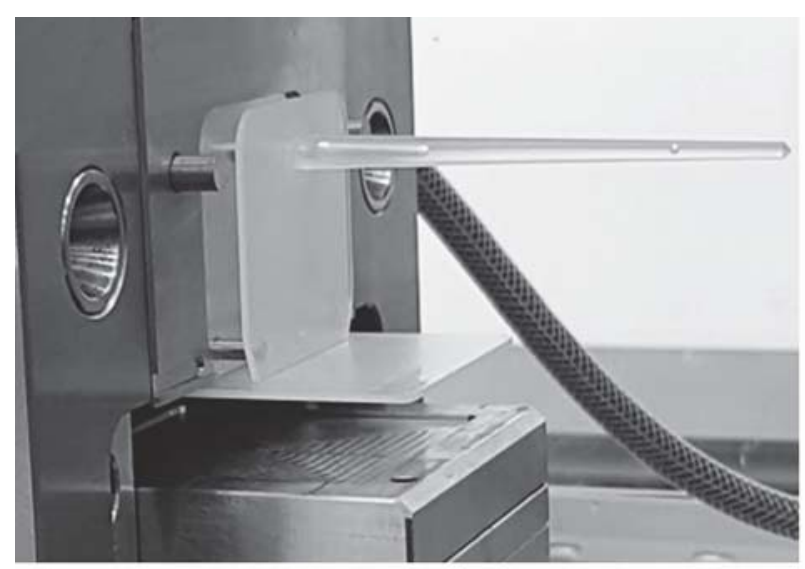

a)

Figure 7. Overmolded parts in the mold: (a) good welding, produced with the lower crystallinity base plates (b) the rib and plate fell apart, caused by the high crystallinity of the base plate. with a higher crystalline fraction - manufactured in a hotter mold - it could not. Therefore, in the case of PLA $3100 \mathrm{HP}$ and a melt temperature of $210^{\circ} \mathrm{C}$, the success of overmolding depends on the crystalline fraction of the preform - the lower the better.

\subsection{Overmolding onto a printed plate}

In the case of the FDM technology, the surface roughness of the preform depends on the build orientatio - the side on the printing bed has better surface roughness than that of the printing side. We manufactured 20 samples and injection molded PLA $3100 \mathrm{HP}$ on the rougher side of 10 and on the smoother side of the other 10 . The melt temperature was 210 and $250^{\circ} \mathrm{C}$. After FDM printing, the preforms were stored at room temperature at a relative humidity of $50 \%$, and within a few hours we overmolded on them. In each series, we measured the $R_{\mathrm{a}}$ and $R_{\mathrm{z}}$ surface roughness values of 3 samples. They were 0.07 and $2.13 \mu \mathrm{m}$ on the printing bed side of the part, and 3.13 and $30.37 \mu \mathrm{m}$ on the printing side, respectively.

As we showed earlier, increasing melt temperature significantly improves bond strength, and so in the case of both surface roughness levels, bond strength improved as melt temperature was increased (Figure 8).

We proved with two-sample t-test that surface roughness only has an effect in the case of the lower temperature; when melt temperature is higher, surface roughness does not affect the bond strength. This is probably because proper welding not only require high enough melt temperature to provide the adequate amount of heat but the heat must also be transferred to the preform, which depends on the heat transfer coefficient. In the case of the higher melt

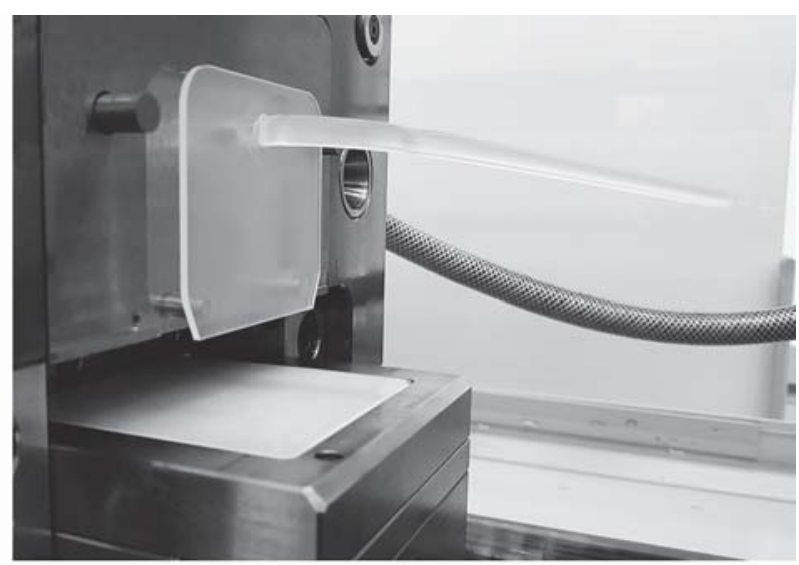

b) 


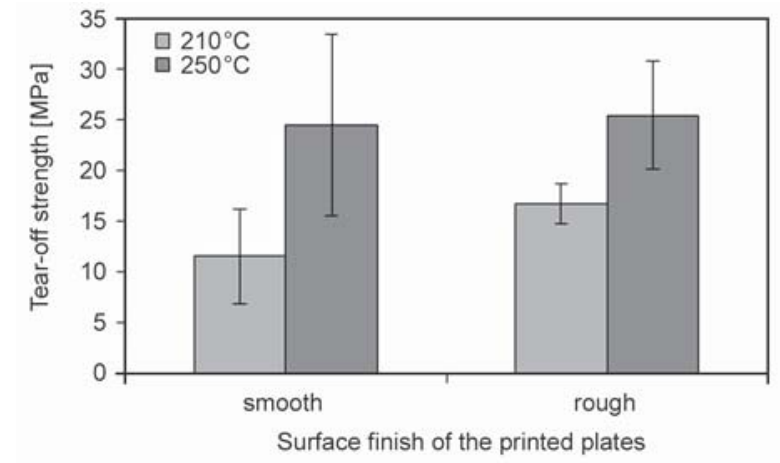

Figure 8. The effect of the surface quality of preforms manufactured by FDM (smooth: $R_{\mathrm{a}}=0,07 \mu \mathrm{m}, R_{\mathrm{z}}=$ $2,13 \mu \mathrm{m}$, rough: $\left.R_{\mathrm{a}}=3,13 \mu \mathrm{m}, R_{\mathrm{z}}=30,37 \mu \mathrm{m}\right)$ on the bond strength between the overmolded rib and the preform.

temperature, the preform can be melted when the contact surface has lower surface roughness, even though the contact area is smaller. On the other hand, in the case of the lower melt temperature, surface roughness may have a significant effect through the efficiency of heat transfer.

Crystallinity, similar to the injection molded samples, had a negative effect on bond strength. The crystallinity of the printed plates was low, around $1.3 \%$. In the overmolding experiments, these produced better bond strength than the plates whose crystallinity was increased to around $42 \%$ by heat treatment (Figure 9).

We also injection molded preforms from pellets obtained by grinding PLA 040 printed samples. Then we overmolded ribs on them to examine the possibility of recycling. We used a two-sample t-test to show that there is significant difference between the original PLA and the recycled PLA. This is because grinding impairs quality. However, this difference is

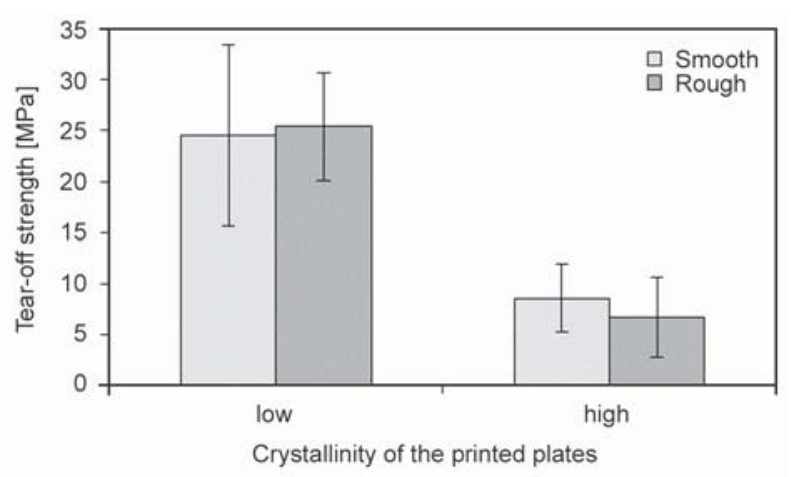

Figure 9. The effect of the crystallinity (low: 1.3\%; high: $42 \%$ ) and surface roughness (smooth: $R_{\mathrm{a}}=0,07 \mu \mathrm{m}$, $R_{\mathrm{z}}=2,13 \mu \mathrm{m}$; rough: $\left.R_{\mathrm{a}}=3,13 \mu \mathrm{m}, R_{\mathrm{z}}=30,37 \mu \mathrm{m}\right)$ of plates produced by FDM on the bond strength between the overmolded rib and the preform. negligible from an engineering point of view. The original $52.0 \mathrm{MPa}$ bond strength only decreased to $48.9 \mathrm{MPa}$ as a result of recycling.

\subsection{Overprinting onto a molded plate}

In overprinting, a new issue emerged. During printing, the surface has to be cooled with fans (Figure 10); without this the surface quality of the printed product cannot be ensured. This, however, takes a great deal of heat away from the surface and this impairs welding.

We examined the result of using the cooling fans during overprinting. We manufactured a series with the fans turned on (normal use) and another series with the fans turned off. As expected, bond strength was significantly lower than with the fans turned off (Figure 11).

\subsection{Overprinting onto a printed plate}

Since overprinting onto a printed part does not have much practical significance, in this case we examined the effect of printing direction. As expected,

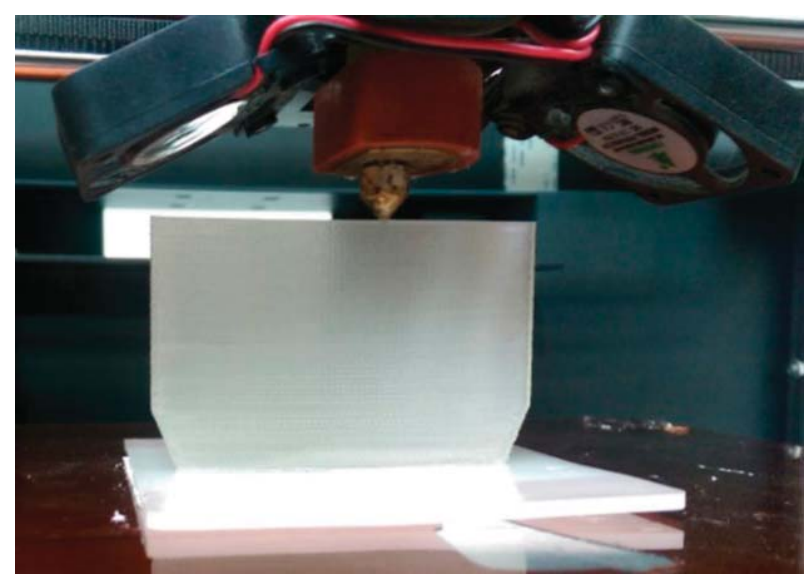

Figure 10. FDM printer with the cooling fans during printing.

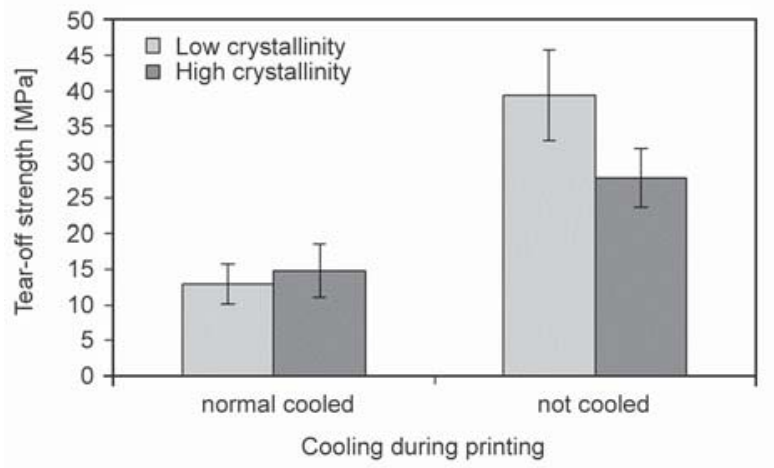

Figure 11. Tear-off strength in the case of overprinted ribs onto injection molded plates with and without the cooling fan (low crystallinity was about $21.0 \%$, while high crystallinity was around $32.8 \%$ ). 


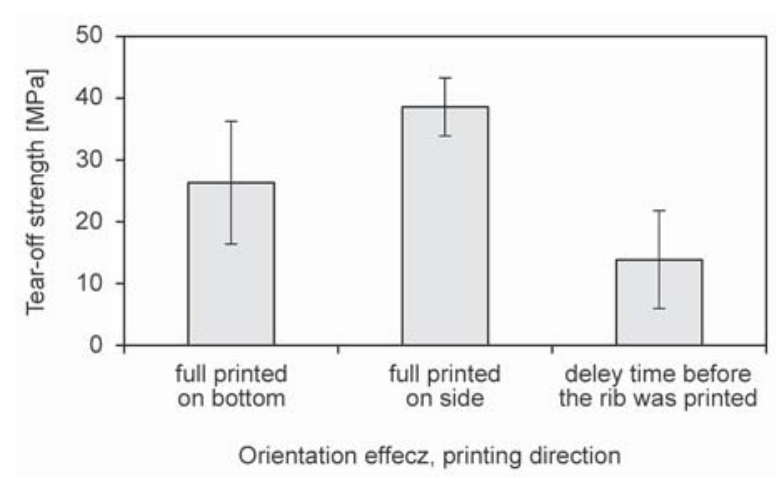

Figure 12. Printing orientation effect on tear-off strength.

based on the literature review, the products which were printed on their sides had significantly higher strength than those that stood on their base plate during printing. The weakest were those where the plate was produced and then the rib was overprinted on it later on (Figure 12). This is obvious, as in the latter case the rib - as if it had been overprinted onto the plate - was printed on the finished plate. Since the fan was turned on in this case, cooling had a significant effect on bond strength. To check the effect of cooling, we waited for 10 minutes after the base plate was manufactured, which meant extra cooling, before we continued printing. As expected, this further reduced bond strength as the heated print bed of the FDM printer was not able to heat up the whole printed plate.

We proved the effect of cooling with a thermal imaging camera (FLIR). Although the temperature of the printing bed was set to $60^{\circ} \mathrm{C}$, the surface temperature of the plate barely reached $50^{\circ} \mathrm{C}$, which is the effect of the fans (Figure 13).

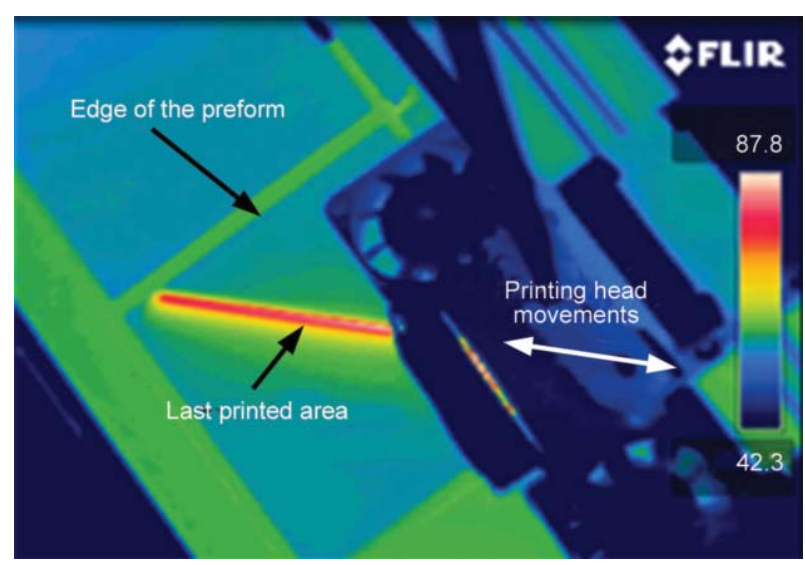

Figure 13. Thermal camera image during the printing of the preform.

\section{Conclusions}

We showed the possibilities of combining two of today's most important polymer processing technologies: injection molding and 3D printing. We also introduced a novel concept to study and compare the bonding strength of polylactic acid (PLA) parts prepared by overprinting and overmolding. To achieve this, we designed an injection mold that facilitates overmolding a rib onto an injection molded or 3D printed preform inserted in the mold. Overprinting was performed with an identical geometry, therefore we were able to compare the results. We showed the effect of melt temperature on welding, but at the same time, we proved with TGA that residence time during injection molding can have a weakening effect due to degradation. We also proved that in overmolding the crystallinity of the preform is one of the most important properties from the point of view of welding. Amorphous preforms had higher bond strength, which can be explained with the lower amount of heat necessary for melting. The increase in crystallinity impairs welding, or can even prevent bonding altogether. On the other hand, higher surface roughness can improve welding due to the higher contact area. We proved with a thermal imaging camera during 3D printing that cooling the surface at the beginning of printing greatly impairs the mechanical strength of the product, therefore we suggest not using cooling for some time at the beginning of printing.

As an overall result, we have proved that injection molded and 3D printed parts can be joined well. We examined all four combinations: overmolding onto a molded or printed plate and overprinting onto a molded or printed plate.

\section{Acknowledgements}

This work was supported by the National Research, Development and Innovation Office, Hungary (NVKP_16-1-20160046) and by the Higher Education Excellence Program of the Ministry of Human Capacities in the framework of the Nanotechnology research area of the Budapest University of Technology and Economics (BME FIKP-NANO).

\section{References}

[1] Chow W. S., Leu Y. Y., Mohd Ishak Z. A.: Mechanical, thermal and morphological properties of injection molded poly(lactic acid)/calcium carbonate nanocomposites. Periodica Polytechnica Mechanical Engineering, 60, 15-20 (2016).

https://doi.org/10.3311/PPme.8319 
[2] Datta R., Henry M.: Lactic acid: Recent advances in products, processes and technologies - A review. Journal of Chemical Technology and Biotechnology, 81, 1119-1129 (2006).

https://doi.org/10.1002/jctb.1486

[3] Auras R. A., Harte B., Selke S., Hernandez R.: Mechanical, physical, and barrier properties of poly(lactide) films. Journal of Plastic Film and Sheeting, 19, 123-135 (2003). https://doi.org/10.1177/8756087903039702

[4] Lim L-T., Auras R., Rubino M.: Processing technologies for poly(lactic acid). Progress in Polymer Science, 33, 820-852 (2008).

https://doi.org/10.1016/j.progpolymsci.2008.05.004

[5] Kuznetsov V. E., Solonin A. N., Urzhumtsev O. D., Schilling R., Tavitov A. G.: Strength of PLA components fabricated with fused deposition technology using a desktop 3D printer as a function of geometrical parameters of the process. Polymers, 10,313/1-313/11 (2018). https://doi.org/10.3390/polym10030313

[6] Matsuzaki R., Tsukamoto N., Taniguchi J.: Mechanical interlocking by imprinting of undercut micropatterns for improving adhesive strength of polypropylene. International Journal of Adhesion and Adhesives, 68, 124-132 (2016).

https://doi.org/10.1016/j.ijadhadh.2016.03.002

[7] de Lucas-Freile A., Sancho-Querol S., Yáñez-Pacios A. J., Marín-Perales L., Martín-Martínez M.: Blends of ethylene-co-vinyl acetate and poly(3-hydroxybutyrate) with adhesion property. Express Polymer Letters, 12, 600-615 (2018).

https://doi.org/10.3144/expresspolymlett.2018.51

[8] Pal K., Panwar V., Friedrich S., Gehde M.: An investigation on vibration welding of amorphous and semicrystalline polymers. Materials and Manufacturing Processes, 31, 372-378 (2016).

https://doi.org/10.1080/10426914.2015.1019111

[9] Amancio-Fiho S. T., Dos Santos J. F.: Joining of polymers and polymer-metal hybrid structures: Recent developments and trends. Polymer Engineering and Science, 49, 1461-1476 (2009).

https://doi.org/10.1002/pen.21424

[10] Carello M., Amirth N., Airale A. G., Monti M., Romeo A.: Building block approach' for structural analysis of thermoplastic composite components for automotive applications. Applied Composite Materials, 24, 13091320 (2017).

https://doi.org/10.1007/s10443-017-9592-x

[11] Nguyen S., Perez C. J., Desimone M., Pastor J. M., Tomba J. P., Carella J. M.: Adhesion control for injection overmolding of elastomeric propylene copolymers on polypropylene. Effects of block and random microstructures. International Journal of Adhesion and Adhesives, 46, 44-55 (2013).

https://doi.org/10.1016/j.ijadhadh.2013.05.016
[12] Donderao M., Pastor J. M., Carella J. M., Perez C. J.: Adhesion control for injection overmolding of polypropylene with elastomeric ethylene copolymers. Polymer Engineering and Science, 49, 1886-1893 (2009). https://doi.org/10.1002/pen.21415

[13] Carella A. R., Alonso C., Merino J. C., Pastor J. M.: Sequential injection molding of thermoplastic polymers. Analysis of processing parameters for optimal bonding conditions. Polymer Engineering and Science, 42, 2172-2181 (2002). https://doi.org/10.1002/pen.11107

[14] Zsíros L., Kovács J. G.: Surface homogeneity of injection molded parts. Periodica Polytechnica Mechanical Engineering, 62, 284-291 (2018). https://doi.org/10.3311/PPme.12128

[15] Török D., Kovács J. G.: Effects of injection molding screw tips on polymer mixing. Periodica Polytechnica Mechanical Engineering, 62, 241-246 (2018).

https://doi.org/10.3311/PPme.12183

[16] Huang D. Y., Chen R. S.: Bonding strength at solid-melt interface for polystyrene in a sequential two-staged injection molding process. Polymer Engineering and Science, 39, 2159-2171 (1999).

https://doi.org/10.1002/pen.11605

[17] Arzonda L. M., Pino N., Carella J. M., Pastor J. M., Merino J. C., Póveda J., Alonso C.: Sequential injection overmolding of an elastomeric ethylene-octene copolymer on a polypropylene homopolymer core. Polymer Engineering and Science, 44, 2110-2116 (2004). https://doi.org/10.1002/pen.20216

[18] Ananthanarayanan A., Gupta S. K., Bruck H.: Characterization and control of plastic deformation in mesoscale premolded components to realize in-mold assembled mesoscale revolute joints. Polymer Engineering and Science, 49, 293-304 (2009).

https://doi.org/10.1002/pen.21257

[19] Dizon J. R. C., Espera Jr A. H., Chen Q., Advincula R. C.: Mechanical characterization of 3D-printed polymers. Additive Manufacturing, 20, 44-67 (2018).

https://doi.org/10.1016/j.addma.2017.12.002

[20] Tymrak B. M., Kreiger M., Pearce J. M.: Mechanical properties of components fabricated with open-source 3 -D printers under realistic environmental conditions. Materials and Design, 58, 242-246 (2014). https://doi.org/10.1016/j.matdes.2014.02.038

[21] Calafel M. I., Aguirresarobe R. H., Sadaba N., Boix M., Conde J. I., Pascual B., Santamaria A.: Tuning the viscoelastic features required for 3D printing of PVC-acrylate copolymers obtained by single electron transfer-degenerative chain transfer living radical polymerization (SET-DTLRP). Express Polymer Letters, 12, 824-835 (2018).

https://doi.org/10.3144/expresspolymlett.2018.70 
[22] Wang G. X., Liu P., Zhang W., Zhen Z. C., Wang X. W., Lu B., Wang P. L., Ji J. H.: Preparation and characterization of novel $\mathrm{PA} 6 / \mathrm{SiO}_{2}$ composite microsphere applied for selective laser sintering. Express Polymer Letters, 12, 13-23 (2018).

https://doi.org/10.3144/expresspolymlett.2018.3

[23] Chiulan I., Frone A. N., Brandabur C., Panaitescu D. M.: Recent advances in 3D printing of aliphatic polyesters. Bioengineering, 5, 2/1-2/18 (2018). https://doi.org/10.3390/bioengineering5010002

[24] Wang X., Jiang M., Zhou Z., Gou J., Hui D.: 3D printing of polymer matrix composites: A review and prospective. Composites Part B: Engineering, 110, 442458 (2017).

https://doi.org/10.1016/j.compositesb.2016.11.034

[25] Gao W., Zhang Y., Ramanujan D., Ramani K., Chen Y., Williams C. B., Wang C. C. L., Shin Y. C., Zhang S., Zavattieri P. D.: The status, challenges, and future of additive manufacturing in engineering. ComputerAided Design, 69, 65-89 (2015).

https://doi.org/10.1016/j.cad.2015.04.001
[26] Ngo T. D., Kashani A., Imbalzano G., Nguyen K. T. Q., Hui D.: Additive manufacturing (3D printing): A review of materials, methods, applications and challenges. Composites Part B: Engineering, 143, 172-196 (2018). https://doi.org/10.1016/j.compositesb.2018.02.012

[27] Zink B., Kovács J. G.: Enhancing thermal simulations for prototype molds. Periodica Polytechnica Mechanical Engineering, 62, 320-325 (2018). https://doi.org/10.3311/PPme.12526

[28] Mark G. T.: Embedding 3d printed fiber reinforcement in molded articles. U.S. Patent 20170120519 A1, USA (2017).

[29] Li H., Huneault M. A.: Effect of nucleation and plasticization on the crystallization of poly(lactic acid). Polymer, 48, 6855-6866 (2007).

https://doi.org/10.1016/j.polymer.2007.09.020 